\title{
Synthetic Derivatives of Artemisinin and Cancer
}

\author{
Amit Sarder ${ }^{1}$, Yuba Raj Pokharel ${ }^{1 *}$ \\ Faculty of Life Sciences \& Biotechnology, South Asian University (A University run by 8 SAARC nations), New Delhi, \\ 110021, India.
}

\begin{abstract}
Curing of cancer or at least prolonging the life of a cancer patient can be done by the development of anticancer drugs which can kill the cancer cells selectively. Artemisinin (ART), a natural endoperoxide containing sesquiterpene lactone, is a naturally occurring antimalarial with potent anticancer properties. Despite high efficacy, the therapeutic value of ART is limited by its low solubility in oil and water, short half-life after administration, poor bioavailability etc. In order to avoid these limitations, several derivatives of artemisinin have been synthesized which are more active than the parent artemisinin molecule and also exhibit enhanced anticancer activity in nano-to-micro molar range. Thus, ART derivatives can be a good treatment option for cancer treatment. However, further research is needed in order to develop better ART derivatives with greater efficacies. Again, the use of ART derivatives in cancer treatment must be addressed by better understanding of the mechanism of action of the derivatives which will help to increase the clinical effectiveness of the derivatives. The aim of this review paper is to provide an overview about ART, its synthetic derivatives and their anticancer properties.
\end{abstract}

Keywords: Artemisinin, Synthetic Derivatives, Cancer

\section{INTRODUCTION}

Cancer is a life threatening disease. The global incidence of cancer is increasing day by day. Globally, the five most common cancers in both male and female include lung cancer, breast cancer, colorectal cancer, prostate cancer and cancer of cervix uteri. In United States, 1 in 4 deaths is due to cancer. Though the pattern of cancer incidence varies among geographical regions, it has become a public health burden all over the world [1,2]. Curing of cancer or at least prolonging the life of a cancer patient can be done by the development of anticancer drugs which can kill the cancer cells selectively. Natural products are good source of compounds having inhibitory effects against a range of diseases. Thus, the isolation of artemisinin (ART) from Artemisia аппиа $\mathrm{L}$. is a great success of pharmacognosy [3]. Though ART is well known for its anti-malarial properties, ART and its derivatives also have antiinflammatory, anti-tumor, anti-angiogenic and antiproliferation properties. Thus, it has received a special attention in cancer research [4].

\section{* Correspondence: Yuba Raj Pokhrel}

Assistant Professor, Faculty of Life Sciences \&

Biotechnology, South Asian University, New Delhi

E-mail: yrp@sau.ac.in

\section{Artemisinin:}

Artemisinin (ART) is a natural endoperoxide containing sesquiterpene lactone isolated from an ancient Chinese herb Artemisia апnиa L. (Qinghao), one kind of wormwood native to Asia. ART is also known as Qinghaosu and it was discovered by Tu Youyou in the early 1970s [5].The use of Artemisia аппиа L. for treatment of diseases was reported in Chinese scripts as early as 168 BC. Later on, Qinghaosu was isolated from the shoots of Artemisia annua L. in pure form and its structure was determined in 1979 [6]. It is a potent antimalarial drug approved by the Food and Drug Administration (FDA). It is also a best therapeutic against drug resistance and has shown effectiveness against infectious diseases like hepatitis B and schistosomiasis. Recently, effectiveness of ART against different cancer cell lines including colon cancer, breast cancer and human leukemia has been reported and it may be effective in the treatment of drug resistant cancers. As ART is a natural product, it has no or fewer side effects [5-7]. Recent studies have also suggested the immunosuppressive activity of ART and it is used to treat autoimmune disease like rheumatoid arthritis, systemic lupus erythematosus and collagen-induced arthritis [8]. 


\section{Biosynthesis of Artemisinin:}

Artemisia апnиa L. uses the sugars produced by photosynthesis in plants and convert them to two-carbon acetyl-CoA in the cytosol. The two-carbon acetyl-CoA enters into the cytosolic mevalonate biosynthesis pathway and produces 15-carbon farnesyldiphosphate (FDP). The next step is the conversion of FDP into 15-carbon isoprenoid hydrocarbon amorphadiene by amorphadiene synthase (ADS) which is the first commited step of artemisinin biosynthesis. Amorphadiene is oxidized enzymatically to either dihydroartimisinic acid or artimisinic acid. Dihydroartimisinic acid is a direct precursor of artemisinin and in presence of sunlight it is converted spontaneously into artemisinin $[7,9,10]$.

\section{Artemisinin and Its Derivatives:}

ART is a potent antimalarial and can kill malarial parasite very quickly. Despite high efficacy and quick action over malarial parasites, the therapeutic value of ART is limited by its low solubility in oil and water which causes difficulties in the intravenous administration of ART. ART has also short half-life after administration. Again, ART has relatively high recurrence rate of infection in monotherapy. Although ART is considered to be of low toxicity, there are evidences of reproductive toxicity and neurotoxicity. ART has also poor bioavailability which also limits its effectiveness. These limitations inspired the development of synthetic ART with better pharmacological properties than parent molecule. Thus, development of new drugs based on the parent ART has become a new area of investigation [10-12].

To overcome some of these limitations, several synthetic and semi-synthetic derivatives of ART have been developed. The semi-synthetic derivatives of ART include artesunate (ARS), dihydroartemisinin (DHA), artemether $(\mathrm{AM})$, arteether (AE) etc. ART along with its semisynthetic derivatives are considered as first-generation endoperoxides. Though ART has low solubility in water and oil, ARS is water-soluble and AM and AE are oilsoluble. The synthetic derivatives of ART exhibit increased stability and potency and are considered as second-generation endoperoxides. All these semi-synthetic and synthetic derivatives of ART show greater potency, improved solubility and are effective at micromolar to nanomolar concentrations [13]. For example, artesunic acid, a semi-synthetic analog of ART, shows greater toxicity towards cancer cells but exhibits low toxicity towards normal cells [14]. DHA and ARS both act as radiosensitiser for cervical cancer cells [15].

Again, anticancer activity of ART can be improved by preparing hybrid drugs. Hybrid drugs are prepared by incorporating two drugs into a single molecule. Hybrid drugs are less prone to drug resistance and have the capacity to impact multiple targets simultaneously. For instance, the strong antiangiogenic activity of ARTglycolipid hybrid has been reported in recent times [16].

Table 1: Artemisinin and its derivatives.

\begin{tabular}{lll}
\hline Code & $\begin{array}{l}\text { Artemisinin and } \\
\text { its derivatives }\end{array}$ & $\begin{array}{l}\text { Molecular } \\
\text { Weight (g/mol) }\end{array}$ \\
\hline ART & Artemisinin & 282.33 \\
ARS & Artesunate & 384.42 \\
DHA & Dihydroartemisinin & 284.35 \\
AD1 & Anhydrodihydroartemisinin & 266.33 \\
AD2 & 10-dihydroartemisinyl acetate & 326.38 \\
AD3 & 10-dihydroartemisinyl butyrate & 354.44 \\
AD4 & 10-(2'-butyloxy) dihydroartemisinin & 340.38 \\
AD5 & 10-dihydroartemisinyl 2'-propylpentanoate & 410.54 \\
AD6 & 10-dihydroartemisinyl 2', 2'-dimethylpropionate & 368.46 \\
AD7 & 10-dihydroartemisinyl perfluoropropionate & 430.36 \\
AD8 & 10-dihydroartemisinyl dimethylcarbamate & 355.43 \\
AM & Artemether & 298.375 \\
AE & Arteether
\end{tabular}
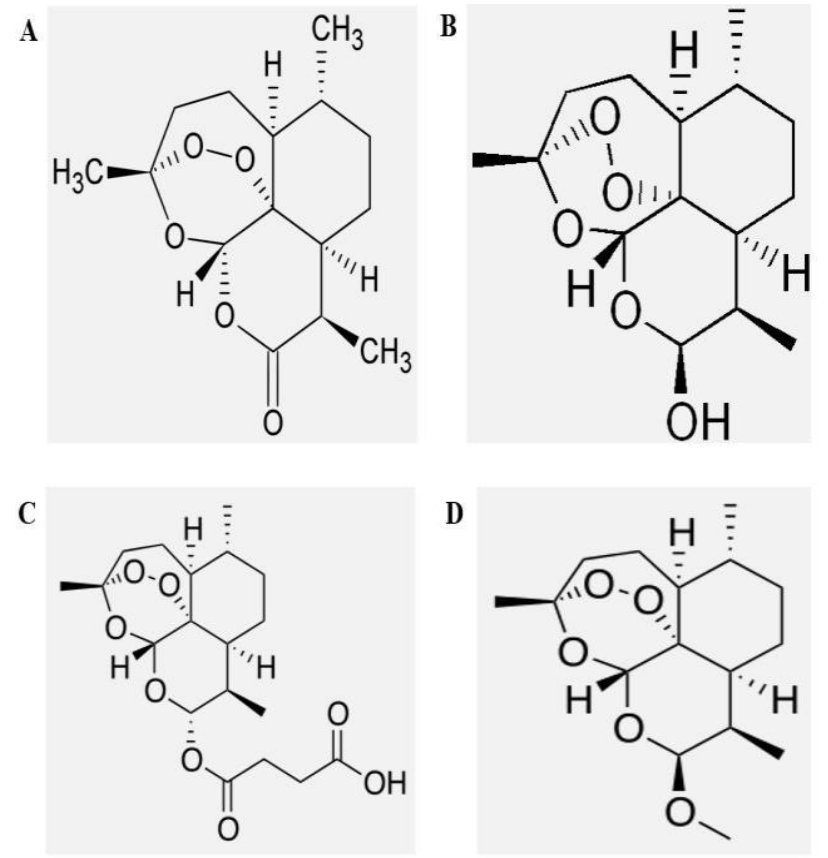

Figure 1: Chemical structure of artemisinin and its several derivatives. A. Chemical structure of artemisinin (ART). B. Chemical structure of dihydroartemisinin (DHA). C. Chemical structure of artesunate (ARS).D. Chemical structure of artemether (AM). 


\section{Mechanism of Action of Artemisinin:}

The structure of ART contains an endoperoxide bridge (C$\mathrm{O}-\mathrm{O}-\mathrm{C})$. This endoperoxide bridge is pharmacologically very important because this is required for the antimalarial activity. Although the precise mechanism of action of ART is not very clear, it is thought that the endoperoxide bond is activated by ferrous iron (FeII) or by reduced heme (FPFeII).The activation of endoperoxide bond generates cytotoxic carbon-centered free radicals. These carboncentered free radicals are potent alkylating agent which may target the macromolecules of malarial parasite leading to the death of the parasites [17].

The antitumor mechanism of action of ART is not clearly defined. But, it is proposed that the antitumor mechanism of action of ART is based on the similar antimalarial mechanism of action of ART. Thus, the endoperoxide bridge is also thought to be responsible for the antitumor mechanism of action of ART [14]. Cancer cells possess more intracellular free iron than normal cells because cancer cells require high amount of iron for their proliferation and growth. Thus, for uptaking higher amount of iron, cancer cells exhibit higher amount of transferrin receptors (TfR). Although the level of TfR may vary in different cell lines, they differ significantly from normal cells. It is thought that iron-activation of endoperoxide bridge of ART is a crucial event for cytotoxicity because compounds without endoperoxide bridge don't exhibit cytotoxicity. Iron-activated endoperoxide bridge of ART generates radical oxygen species (ROS) and carboncentered radicals which lead to cell alterations or cell death. Cancer cells are vulnerable to ROS-induced damage because they exhibit low levels of antioxidant enzymes than normal cells [17-19].

Generally, cell death can proceed either via apoptosis or necrosis. Previously, it was thought that necrosis is an accidental cell death which occurs in response to physiochemical insults. But, recent studies suggest that necrosis can also be a regulated event and thus it is now defined as genetically controlled cell death event resulting in cellular leakage and characterized by cell swelling, cell lysis, cytoplasmic granulation and organelle dysfuntion $[20,21]$. On the other hand, apoptosis is a distinctive form of programmed cell death characterized by distinct biochemical mechanisms and morphological characteristics. It is an intrinsic cell-suicide program which ensures proper development by maintaining tissue homeostasis and safeguarding the organism through the elimination of unwanted or virus-infected cells. This active, metabolic, genetically encoded and evolutionary selected death pathway can occur under either pathological or physiological conditions and this pathway is characterized by membrane blebbing, chromatin condensation, nuclear fragmentation, cell shrinkage etc.
Ultimately, the cells break into apoptotic bodies which are cleared by phagocytosis [22-24]. Again, there are two major known signaling cascades of classical apoptosis. One major pathway of classical apoptosis is the receptormediated pathway or the extrinsic pathway. Another major pathway for the initiation of apoptosis is the mitochondrial pathway or the intrinsic pathway [25, 26]. Both of these pathways are linked and involve caspases. It has been found that endoperoxide-mediated cytotoxicity can proceed via initiation of caspase-dependent apoptosis in cancer cells. But, the chemical basis of this initiation event is not clearly defined [19, 24].

Furthermore, recent studies suggest that antitumor mechanism of action of ART also involves growth inhibition, increase in the levels of oxidative stress, the inhibition of angiogenesis and metastasis, DNA double strand breakage [14, 15, 27]. Mechanisms like down regulation of the expression of vascular endothelial growth factor and suppression of hyperactive $\mathrm{Wnt} / \beta$-catenin pathway have also been suggested for anticancer activity of ART [28].

\section{Anticancer Activity of Artemisinin and Its Derivatives:}

Anticancer activity of ART and its derivatives have been reported in various types of cancers like breast cancer [29-31], prostate cancer [33], leukemia [34], cervical cancer [32]. Recent studies suggest that ART derivatives can induce apoptosis in cancer cell lines. It can also downregulate proteins involved in cell cycle, oncogenesis and apoptotic resistance like cyclin D1, c-myc, surviving etc. In breast cancer cells, ART derivatives have role in inhibiting growth of breast cancer cells through induction of downregulation of HER family members [35]. Leukemic cells generally contain excess iron in their cytoplasm. These excess iron increases the reactivity of ART for leukemic cells. Thus, ART has also inhibitory effects on leukemic cells [34]. In cervical cancer treatment, ART is considered as a potent radiosensitizer. It acts as a radiosensitizer through regulation of G-2 check-point related proteins. Thus, it improves the therapeutic ratios of cervical cancer treatment by combination of ART with ionizing irradiation. Again, the anti-cancer action of ART and its derivatives on prostate cancer cells is also reported. Morrissey et al. have reported that ART derivatives can induce apoptosis which follows mitochondrial pathway in prostate cancer cells. Thus, ART derivatives can be a treatment option against prostate cancer cells [36]. 


\section{DISCUSSION:}

ART derivatives are not only good anti-malarials, but also they have anti-inflammatory, anti-angiogenic and antiproliferation properties. They have a broad range of action and are effective against different types of cancer cell lines. They have high specificity towards cancer cells than normal cells. Thus, ART derivatives can be considered as a good treatment option for cancer. But, still there are several aspects which require further research in order to develop better ART derivatives with greater efficacies. Further research is also required for better understanding of the molecular mechanism of action of ART derivatives because it will help to increase the clinical effectiveness of ART derivatives.

\section{ABBREVIATIONS:}

$\begin{array}{ll}\text { ART } & \text { Artemisinin } \\ \text { FDA } & \text { Food and Drug Administration } \\ \text { FDP } & \text { Farnesyl Diphosphate } \\ \text { ADS } & \text { Amorphadiene Synthase } \\ \text { ARS } & \text { Artesunate } \\ \text { DHA } & \text { Dihydroartemisinin } \\ \text { AM } & \text { Artemether } \\ \text { AE } & \text { Arteether } \\ \text { TfR } & \text { Transferrin Receptors } \\ \text { ROS } & \text { Radical Oxygen Species }\end{array}$

\section{REFERENCES:}

1. Sharma JD, Kalit M, Nirmolia T, Saikia SP, Sharma A and Barman D(2014) Cancer: scenario and relationship of different geographical areas of the globe with special reference to north east-india. Asian Pac J Cancer Prev; 15:3721-29.

2. Saranath D and Khanna A(2014) Current status of cancer burden: global and indian scenario. Biomed Res J; 1:1-5.

3. Suberu JO, Romero-Canelon I, Sullivan N, Lapkin AA and Barker GC(2014) Comparative cytotoxicity of artemisinin and cisplatin and their interactions with chlorogenic acids in MCF7 breast cancer cells. ChemMedChem; 9:2791 - 97.

4. Wang L, Świtalska M, Wang N, Du Z, Fukumoto Y, Diep NK, Kiguchi R, Nokami J, Wietrzyk J and Inokuchi T (2014) Design, synthesis, and biological evaluation of artemisinin-indoloquinoline hybrids as potent antiproliferative agents. Molecules; 19:1902135.

5. Zhu S, Liu W, Ke X, Li J, Hu R, Cui H and Song G(2014) Artemisinin reduces cell proliferation and induces apoptosis in neuroblastoma.Oncol Rep.; 32:1094-100.
6. Weathers PJ, Elkholy S and Wobbe KK(2006) Artemisinin: The biosynthetic pathway and its regulation in Artemisia annua, a terpenoid-rich species. In Vitro Cell. Dev. Biol. - Plant; 42:309-17.

7. Buragohain P, Saikia B, Surineni N, Barua NC, Saxena AK and Suri N(2014) Synthesis of a novel series of artemisinin dimers with potent anticancer activity involving Sonogashira cross-coupling reaction..Bioorg. Med. Chem. Lett.;24:237-39.

8. Shi C, Li H, Yang Y and Hou L (2015) Antiinflammatory and immunoregulatory functions of artemisinin and its derivatives. Mediators Imflamm.; 2015:1-7.

9. Paddon CJ and Keasling JD(2014) Semi-synthetic artemisinin: a model for the use of synthetic biology in pharmaceutical development. Nat Rev Microbiol; 12:355-67.

10. Brown $\mathrm{GD}(2010)$ The biosynthesis of artemisinin (Qinghaosu) and the phytochemistry of Artemisia annua L. (Qinghao). Molecules; 15:7603-98.

11. Li J and Zhou B(2010) Biological Actions of Artemisinin: Insights from Medicinal Chemistry Studies. Molecules; 15:1378-97.

12. Medhi B, Patyar S, Rao RS, Byrav DS P and Prakash A(2009) Pharmacokinetic and toxicological profile of artemisinin compounds: an update. Pharmacology; 84:323-32.

13. Meshnick SR, Taylor TE and Kamchonwongpaisan S(1996) Artemisinin and the antimalarial endoperoxides from herbal remedy to targeted chemotherapy. Microbiol Rev.; 60:301-15.

14. Fröhlich T, Karagöz AC, Reiter C and Tsogoeva SB (2016) Artemisinin-derived dimers: potent antimalarial and anticancer agents. J. Med. Chem.; 59:7360-88.

15. Luo J, Zhu W, Tang Y, Cao H, Zhou Y, Ji R, Zhou X, Lu Z, Yang H, Zhang S and Cao J (2014) Artemisinin derivative artesunate induces radiosensitivity in cervical cancer cells in vitro and in vivo. Radiation Oncology; 9:1-12.

16. Min D, Kim M, Ricci J, Jung S, Kim K, Chung WY, Park KK and Jung M (2014) Synthesis and anticancer activity of novel deoxoartemisinin-glycolipid hybrids. Chem. Pharm. Bull.; 62:446-53.

17. Crespo-Ortiz MP and Wei MQ(2012) Antitumor activity of artemisinin and its derivatives: from a wellKnown antimalarial agent to a potential anticancer drug. J Biomed Biotechnol; 2012:1-18.

18. Lai HC, Singh NP and Sasaki T(2013) Development of artemisinin compounds for cancer treatment. Invest New Drugs;31:230-46.

19. Mercer AE, Maggs JL, Sun XM, Cohen GM, Chadwick J, O’Neill PM and Park BK(2007) Evidence for the involvement of carbon-centered 
radicals in the induction of apoptotic cell death by artemisinin compounds. J Biol Chem.; 282:9372-82.

20. Berghe TV, Linkermann A, Jouan-Lanhouet S, Walczak $H$ and Vandenabeele P(2014) Regulated necrosis: the expanding network of non-apoptotic cell death pathways. Nat Rev Mol Cell Biol.; 15:135-47.

21. Ouyang L, Shi Z, Zhao S, Wang FT, Zhou TT. Liu B and Bao JK(2012) Programmed cell death pathways in cancer: a review of apoptosis, autophagy and programmed necrosis. Cell Prolif: 45:487-98.

22. Wu M, Ding HF and Fisher DE(2001) Apoptosis: molecular mechanisms. Encyclopedia of Life Sciences; 1-8.

23. Reed JC(2000) Mechanisms of apoptosis. Am J Pathol,;157:1415-30.

24. Elmore S(2007) Apoptosis: a review of programmed cell death.ToxicolPathol.;35:495-516.

25. Sarder A, Rabbani M, Chowdhury A and Sobhani M(2015) Molecular basis of drug interactions of methotrexate, cyclophosphamide and 5-fluorouracil as chemotherapeutic agents in cancer. Biomed Res Ther; 2:196-206.

26. Putcha GV, Harris CA, Moulder KL, Easton RM, Thompson CB and Johnson EM Jr(2002) Intrinsic and extrinsic pathway signaling during neuronal apoptosis: lessons from the analysis of mutant mice. J Cell Biol.; 157:441-53.

27. Humphreys C, Cooper AJ, Barbu E, Birch BR and Lwaleed BA(2016) Artemisinins as potentialanticancer agents: uptakedetection in erythrocytes using Fourier transforminfrared spectroscopy and cytotoxicity againstbladder cancer cells. J ClinPathol.; 0:1-6.

28. Jirangkul $\mathrm{P}$, Srisawat $\mathrm{P}$, Punyaratabandhu $\mathrm{T}$, Songpattanaslip T and Mungthin M(2014) Cytotoxic effect of artemisinin and its derivatives on human osteosarcoma cell lines. J Med Assoc Thai.; 97:S21521.

29. Wang S and Sasaki T(2013) Synthesis of artemisinin dimers using the $U g i$ reaction and their in vitro efficacy on breast cancer cells. Bioorg. Med. Chem. Lett.;23:4424-27.

30. Dadgar N, Koohi Moftakhari Esfahani M, Torabi S, Alavi SE and Akbarzadeh A(2014) Effects of nanoliposomal and pegylated nanoliposomal artemisin in treatment of breast cancer. Ind J Clin Biochem; 29:501-4.

31. Gong Y, Gallis BM, Goodlett DR, Yang Y, Lu H, Lacoste E, Lai H and Sasaki T (2013) Effects of transferrin conjugates of artemisinin and artemisinin dimer on breast cancer cell lines. Anticancer Res.; 33:123-32.

32. Gong XM, Zhang Q, Torossian A, Cao J and Fu $\mathrm{S}$ (2012) Selective radiosensitization of human cervical cancer cells and normal cells by artemisinin through the abrogation of radiation-induced G2 block. International Journal of Gynecological Cancer; 22:718-24.

33. Michaelsen FW, Saeed ME, Schwarzkopf J and Efferth T(2015) Activity of Artemisia annua and artemisinin derivatives in prostate carcinoma.Phytomedicine; 22:1223-31.

34. Tilaoui M, Mouse HA, Jaafari A and Zyad A(2014) Differential effect of artemisinin against cancer cell lines. Nat. Prod. Bioprospect.;4:189-96.

35. Zhang YJ, Gallis B, Taya M, Wang S, Ho RJ and Sasak T(2013) pH-responsive artemisinin derivatives and lipid nanoparticle formulations inhibit growth of breast cancer cells in vitro and induce down-regulaion of HER family members.PLoS One; 8:1-8.

36. Morrissey C, Gallis B, Solazzi JW, Kim BJ, Gulati R, Vakar-Lopez F, Goodlett DR, Vessella RL and Sasaki $\mathrm{T}(2010)$ Effect of artemisin43in derivatives on apoptosis and cell cycle in prostate cancer cells. Anticancer Drugs; 21:423-32.

\section{Article History:}

Received: 20 June, 2016

Accepted: 15 August, 2016

Published online: 21 Sep, 2016

\section{For Citation:}

Sarder A, Pokharel YR. Synthetic Derivatives of Artemisinin and Cancer. International Journal of Medicine \& Biomedical Sciences. 2016; 1(4):12-16 